\title{
Overview of Change Patterns and Its Implementation
}

\author{
Dr. Munir Theeb \\ University of Zawia
}

\begin{abstract}
The different change patterns are all based on the principles of underlying of various models of change, used to assess the existing trends in institutions and determine those that need to change, and also their organizational response to organizational pressures,. The organizations find it difficult to contribute to comprehensive development, or to face the challenges of the future through its models and traditional patterns, where many of the features that stress the inappropriateness of these current patterns and receiving non-compliance with the requirements of the change implementation. The purpose of this paper is to provide an overview of the theoretical backgrounds of the research issue relating to patterns of change. This paper explores the contradictions and differences across the organizations in terms of managing their organizational change, and also explores some of the implications of different types of change for change management practice.
\end{abstract}

KEYWORDS: change patterns, types of change, models of change

\section{INTRODUCTION}

"Change patterns allow for high-level process adaptations at the process type as well as the process instance level. Change support features ensure that changes are performed in a correct and consistent way, traceability is provided, and changes are facilitated for users. Both change patterns and change support" (Weber, B., Reichert, M., \& Rinderle-Ma, S. 2007). Certo (1994) affirmed that the main patterns of change in the organization is to change the human resources development, including those owned resources from the values, principles and trends and patterns of thinking and behaviour, leadership and managerial skills, and pointed to the importance of training managers. This discussion provides an overview of the change patterns and describes how to implement its fundamental characteristics. The topic advanced theoretical models of change patterns describes how to implement more advanced types of change using the points of convergence and variation in organizations.

\section{CLASSIFYING OF PATTERNS OF CHANGE}

The following are the most important of change patterns from several dimensions (Al-Salem 2001):

1. In terms of interference in the rights change will bring about.

2. In terms of comprehensiveness.

3. In terms of speed of execution.

4. On the administration's reaction to the change.

1. In terms of interference in the rights change will bring about.

Accordingly, the change is divided to Unplanned Change and Planned Change:

A. Unplanned change (spontaneous): change that is not predicted by the organization and was not prepared for in advance; the organization generates a reaction to meet those conditions, internal or external, requiring emergency change.

B. Planned change: this is achieved due to the desire of rights in the change, identifies goals and change it, and stages and expected results, and contains a maximum of a smooth transition, and contains a clear strategic vision for a future previously undesirable(Wilson 1999).

\section{In terms of inclusiveness:}

The change can be divided accordingly to:

A. Comprehensive change: a radical change, which encompasses all aspects of the organization for a radical and holistic change. Hamel (2000) supports this kind of change, where a partial change to the status quo will not work well.

Farias \& Varma (1998) believe that integrated comprehensive entrances for change and organizational design are more ideal than others, as has been applied by development and organizational change experts and the major consulting institutions, proving its success.

B. Partial change: focuses on some aspects of the organization, either in terms of behavioural or organizational or technological; organizations have resorted to partial change to solve the problems in an emergency.

3. In terms of speed of implementation:

The change is divided according to this principle:

A. Change rapidity: usually associated with minor changes and events that Could be implemented rapidly.

B. Gradual change: change is phasic, which is relatively slow to change (Abu Bakar\& Haider 2001). 
4. In terms of reaction of the management towards change:

It can divide the change according to expected change and unexpected change in two patterns, which are:

A. the expected change: a change that the organization had previously predicted and was favourable, which means that humanitarian intervention is intended to meet the expected changes through extrapolation and understanding of the future effects of surrounding the organization, in order to lead the process of change management, and work toward success by taking all necessary means of designing programmes to deal with expected future conditions both, in the management, concepts and values, and in treating individuals and working groups (Hafez, et al (2001).

B. Unexpected change: a change that has not restored the organization, that they did not foresee, and failed to note signs of change. This kind of change can cause serious damage if not adapted to the organization in an appropriate way (Lawzi 1998)].

5. Organizational change can be classified based on the changes method:

- Anticipatory changes: any planned changes, designed to take advantage and respond to cases expected to occur in the future.

- Reactionary changes: are reactions to the circumstances and certain situations, and is therefore essential in an emergency, in response to events and pressures in the external environment.

\section{In terms of extent of change:}

- Incremental

- Strategic change

The categories of the four main types of change are according to two dimensions: the first dimension is 'the ultimate goal of change (End Result); the second dimension is the 'nature of the change'.

The first dimension (End Result) or the ultimate goal of change is focus on the extent and magnitude to achieve the desired change in the organization; the change may contains a shift in the whole of the organization, or simply making some adjustments.

- Transformation change is change that cannot be conducted within the current work of the organization or within its routine, because it requires a change in the usual aspects of the performance of work. The strategic changes include making changes in format or in the direction of the organization's work in a holistic manner.

- The Realignment is the change in the usual modus operandi. The changes include increasing (or continuing) changes in the subsidiary regulations that relate to the statute of the organization, in order to keep the organization working well.(Nadler\& Tushman1990).

The second dimension is the nature of the change, which refers to the way in which they are applying and implementing change, and change comes here either in one large step (Big Bang)or implemented step by step (or stage by stage) but the events are increasing every time and are systematic and progressive.

\section{The rate of change in the organization can be of two types (Nadler\& Tushman 1994):}

The first type: Incremental changes that occur in periods of instability, or the balance in the organizations, (Atwater \& Atwater 1994).

The second type of change, referred to as continuous change, is the largest type of change, which occurs during periods where there is a situation of imbalance in the organization, as happens when Transformation changes are required (Nadler\& Tushman1994) or when the prevailing regulation is not adequate for the requirements of the markets in which it operates, including the environment, and change becomes necessary for organizational survival( Atwater \& Atwater 1994). In this situation, change is happening at an increasing rate and accelerates gradually; in the management literature this kind of change is referred to as planned change, and change of the second degree. The Final result of the change, and change the nature provide us with an explanation of the four different patterns of change as shown in Fig (1):

\section{Transformation Realignment}

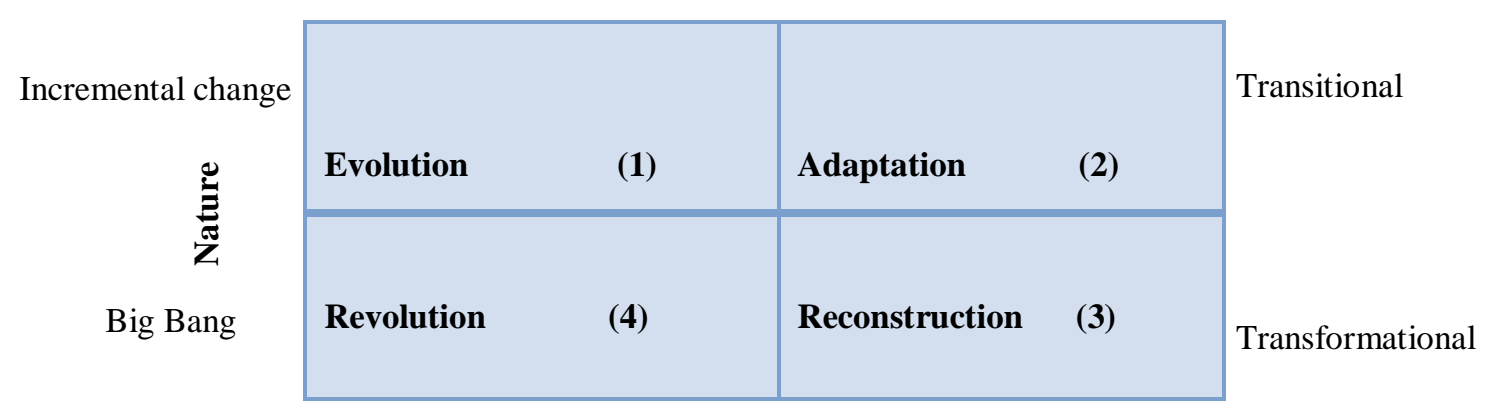

Figure 1. Types of Change (Balogun\& Hailey1999). 


\section{Evolution change:}

The change is aimed at progress and evolution; it is transformational change, meaning that the implementation is gradual, and through various stages and initiatives interrelated to each other, as well as, undertaken by the managers, in response to the anticipation of the need for future change in the organization.

\section{Revolution change:}

Revolution change is underway to transform the organization from the status quo to the other alternative, , and is usually within a relatively short period of time. The change here is mostly exclusive and binding for all, also having a reaction because of the changing competitive conditions faced by the organization.

\section{Adaptation and Reconstruction change:}

Many of the transformational initiatives which aim to transform the work of the organization are very successful. However, these change initiatives revolve around typical reconstruction, or rearranging the organization more than converting from one form into another, since the this type aimed at making organizations more effective . To highlight the complexities of this subject and the difficulty of ensuring the results of the change, it is appropriate to say that some change initiatives which begin with a view to introducing a radical change end with Transformational Change (rebuild the organization) then it becomes difficult to achieve ( Balogun \& Hailey1999).

"It may be difficult to distinguish between an organisational realignment and a transformation, and the end result of change is better described as a continuum rather than as discrete. However, in general terms, a realignment has a greater focus on efficiency and profitability, whereas a transformative change goes beyond this to challenge the assumptions and beliefs of an organisation. The senior management team and other organisational change agents need to be aware of this distinction as transformations require a greater change capability and significantly more investment" Redman. James. (2019)

\section{CLASSIFYING OF PATTERNS OF CHANGE, DEPENDING ON GRUNDY (1993) AND SENIOR (1997)} Grundy (1993) began with the nature of organizational change, which represents 'forms of change' and the basis for this is that many managers see change and realize as a homogeneous concept.

Grundy (1993) classified change into three main types, as shown in Figure (2)

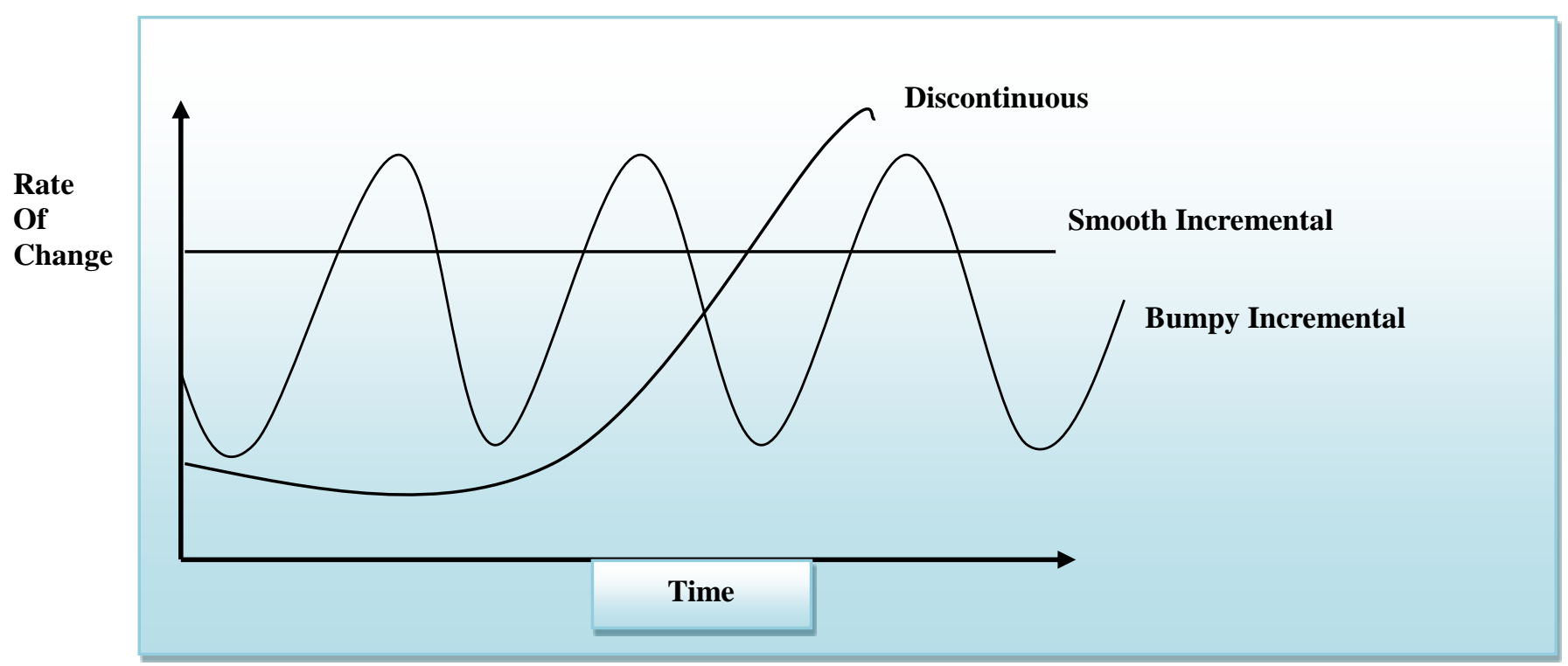

Figure 2. Major Types of Change Senior, B (2002).. [122], [Grundy, T. (1993) [164]

\section{The first pattern: Smooth Incremental Change:}

Smooth incremental change is change that evolves slowly in a systematic and predictable way.

In Figure (2) a vertical line represents Rate of Change, and therefore this figure contains a certain amount of change occurring at rate of smooth incremental change, also includes cvolution change (Senior2002).

The second pattern: Bumpy Incremental Change:

The rate of change increases or decreases in some periods in this type of change, so it becomes uneven and sudden changes occur occasionally.
This kind of change is characterized by a series of systematic and incremental changes, closely followed by abrupt changes, and demonstrated by the protrusions in Fig. (2). These outcrops are due to the continuous changes that occur in external environment, which in turn enable the organization to make regular adjustments in their work consistently without significant side effects (Grundy1993).

The third pattern: Discontinuous Change:

Change is marked by rapid shifts in strategy, structure or culture, or in all three.

Grundy (1993) sees that the change can be found in the rapid changes that occur either in the strategy of the organization, 
in the organizational structure or in the organizational culture, or in any of these three factors together.

\section{POINTS OF CONVERGENCE AND VARIATION IN ORGANIZATIONS:}

It seems that the three types raised by Grundy (1993) are based on personal observation more than on empirical research. The work submitted by Tushman, Newman \& Romanelli (1988), which was based on tests and many of studies conducted on business organizations, and applied practical situations, suggest a model of organizational life consisting of cycles of time where the growing trend of change or deviation reached one point, then stopped and continued intermittently, according to the change. Each of these types of change has a common goal to maintain the appropriate strategy between the organization and between the structure and operations. We find that Fine-tuning, and Incremental Adaptations designed to make improvements on what had been performing well at the base.

(Tushman et al. (1988) shows how the organizations with continued growth become more efficient, and evolve their internal forces to allow them to maintain stability; these same forces eventually generate strong resistance when it tries to change its strategy for some reason, and thus we find during times of radical changes in the regulatory environment, that reasons minor amendments will not lead to drastic changes in strategy or organizational structure, or individuals, or processes [165]. These are the elements that are a requirement for the development of organizations; in such cases (Tushman et al. (1988) find that organizations perform Frame-breaking change.

Thus, the time cycles in the life of any organization where there is relative calm and stability will also occur relatively frequently, leading to a radical organizational change. A radical change is usually applied quickly in order to reverse the growing systematic changes; the scope of radical change including the following:

- Restructuring the organization and its fundamental values, or in other words a new definition to the task of regulation.

- Amendments to develop the organization and its strengths, to reflect changes in competition and resource allocation.

- Reorganization or developing a new strategy requires adjustments in the organizational structure, procedures and regulations, or changes in organizational structure.

- Review of the business models which are overlapping, or taking new measures or in the flow of work or communications network, or in models where decisions are taken.

- Appointing new directors, usually from outside the organization.

Frame-breaking change is a transformative change, meaning that the transformations lead to the restructuring of the nature of the entire organization, through the following steps:
1. Need for cooperation and uniformity in procedures, any need for the solidarity of all parts of the organization in this process.

2. Observation of resistance forces that can grow and evolve when applying radical change slowly.

3. Caution of risk and uncertainty (Senior 2002).

\section{THEORETICAL MODELS OF CHANGE PATTERNS}

\section{The Incremental Model of Change:}

There is no doubt that managers, in response to pressures external and internal environments, constant make their organizations evolve over time, automatically adjusting when there are changes in work and the environment. "Incremental change can be thought of as a process that modifies, adjusts, or refines the status quo via relatively simple and minor changes. Based on this definition, it's important to emphasize that this kind of organizational change, sometimes referred to as first order change, doesn't alter an organization's core. Incremental change refers to relatively minor adjustments, in the grand scheme of things, to pre-existing systems, hierarchies, models, products, services, and processes".(Incremental \& Radical Change: Definition \& Examples, 2019)Mintzberg (1978) finds that organizations with relatively long periods of constant change and increasing regularly, and even in these periods we find other short periods punctuated by sudden and radical change, and indeed, according to the fluctuations that prevailed in the world during the past twenty years, some intellectuals defend the idea that what prevails in organizations currently is the emergence of short periods of stability offset by longer periods of radical or complete change, and this applies to western organizations [169]. Accordingly, attention to this fluctuation between periods of stability followed by further periods of instability or lack of consistency led to the researchers putting forward models which explain this (Handy 1989).

\section{The Continuous Transformation Model of Change:}

This is based on the model of change (transfer of full and consistent) to the notion that the external environment in which those organizations operate is in constant change; namely, any organization continues to change rapidly, drastically and unexpectedly, to keep up with their external environment, thus ensuring their constant survival. According to this model if an organization wants to stay viable they should develop their capacity to change constantly, according to certain principles and institutions. Applying this case largely to business organizations operating in the retail sector, a sector which is changing constantly, we find that the basic feature is continuous regeneration (Greenwald 1996).

\section{Punctuated Equilibrium Model:}

The punctuated equilibrium model (PEM) is an influential model of organizational change that can both advance theory 
and guide managerial action (Wischnevsky \& Damanpour, 2005).

"The punctuated-equilibrium model characterizes groups as exhibiting long periods of inertia, interspersed with brief revolutionary changes triggered primarily by their members' awareness of time and deadline. In the terminology of the five-stage group development model, the group begin by combining the forming and norming stages, then goes through a period of low performance, followed by storming, then a period of high performing and finally, a last meeting of pressured activity and adjourning( "Types of Groups 2013). Scientific research shows that organizations change and grow through what is known as the Punctuated Equilibrium model, which believes that evolution is not a series of gradual changes that are quiet and regular, but temporary (intermittently) sudden violent changes in specific time periods. The Punctuated equilibrium model leads to imbalance in the organization in periods of stability, and therefore requires the organization to keep balanced when moving from one situation to another (Gersick 1991). Figure (3) shows the process of keeping the organization in a balanced manner requires a change that is always on two levels: first, the aim of bringing about change adaptation and new situations; second, change or incitement to create a new situation (Miller, 1998). According to this view of the change process it occurs during the evolution of change over time, evolving and growing gradually, and then ultimately related to each other; these periods are divided into shorter periods of time of radical change spent on any changes or events within that short periods (Tushman \& Moore 1982). The change to the appropriate adjustment is evolutionary in nature and is continuous and fit the concept of work which includes the development of the institution in general; Senge (1990) explains that the Evolutionary model generates new ways to perform the essential work, and sometimes we call such changes 'Transformations' rather than 'Transactions'. It requires great emphasis on aspects of leadership rather than focus on implementation and management. Such changes can be described as dealing with working on the system overall. Figure (3) shows that the intersection points separating the equilibrium model in the interim.

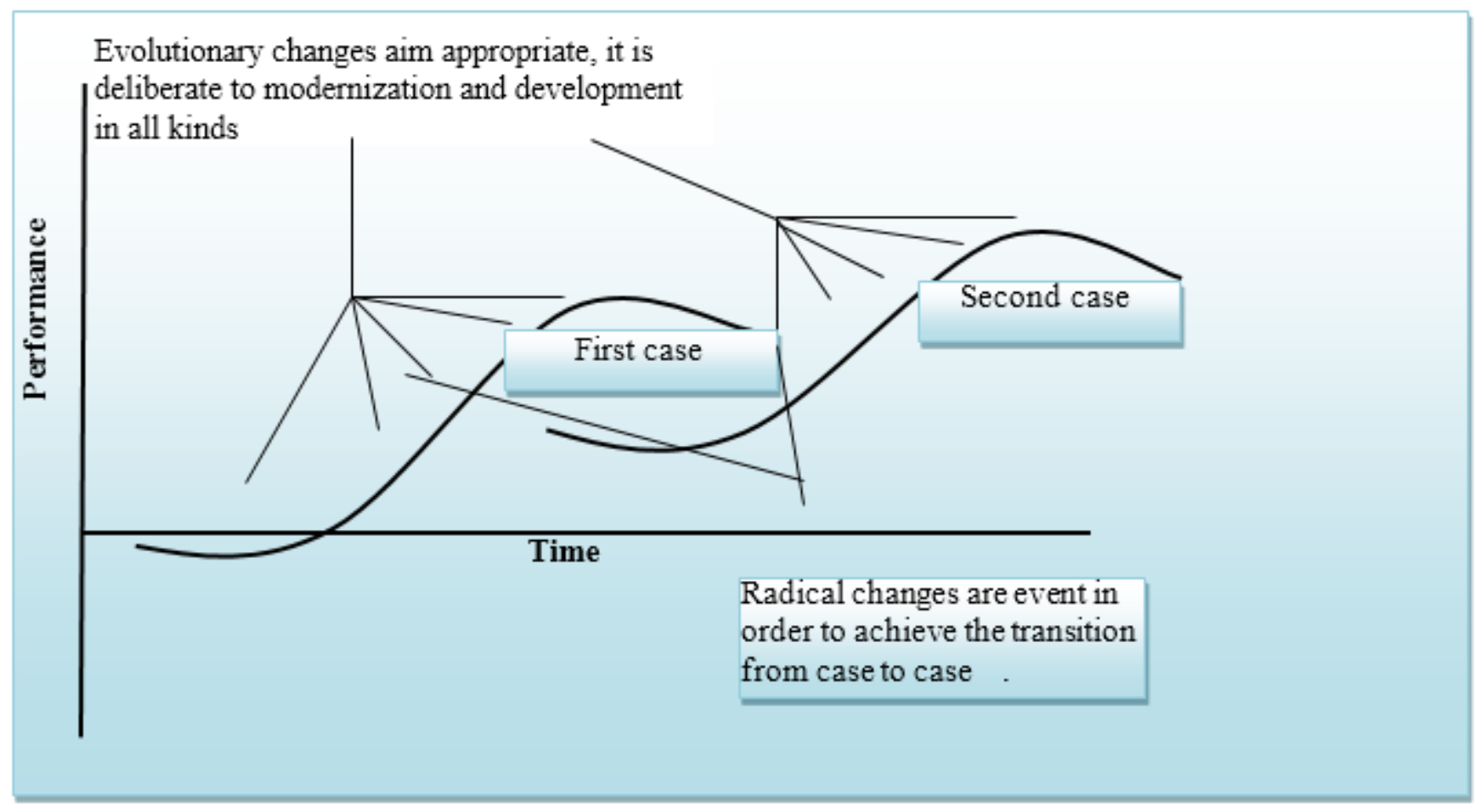

Figure 3. Punctuated Equilibrium Model (Miller, 1998).

The Punctuated Equilibrium Model is seen by the organizations as evolving through long periods of stability, punctuated by attacks from a relatively short radical change (that is, short periods of time characterized by radical changes). These periods of radical change lead to the destabilization of the pattern of the current work of the organization, and to lay the institution for stability in coming periods or periods of new equilibrium (Romanelli and Tushman1994). The difference between the three models is that each model around which the data came from a source differs from other data sources So perhaps it does not seem very strange to us that there are several models of change that are different from one another.

Another reason explains the latest model of change, based on the concept of Organizational life cycles, and is supported by both Kimberley and Miles (1980), who find that the general shape of the life cycle of organizations is first of all the presence, then development, then maturity, and then decline and extinction. These stages can be considered distinct regulatory phases, and thus can be described as different 
stages in which regulatory processes. There is no shortage of information about the reasons for the existence of differences among them, and the reason for the emergence of several models of change, but there is a lack of information that could explain the presence of these differences between the three previous models.

\section{CONCLUSION}

This debate over previous patterns refer to the importance of the topics discussed, and the importance of the different viewpoints put forward by each model, and to realize the importance of the multiple cases and many times it organizational change, all of which also refers to the importance of assessing trends in different change management, according to suitability for different cases in the organizations, and multiple types of change. as well as , regardless of the change format and adopted the goals that seeks to achieve, organizations can expect to achieve success only if those responsible for change management aware of the different directions of change, and the appropriateness of each direction of the special circumstances of the organization.

\section{REFERENCES}

1. Abrahamson, E. (2000)." Change Without Pain", Harvard Business Review, 24 (8) pp.67-81.

2. Abu Bakar, M. \& Haider, M.( 2001) Constraints and requirements of organizational development and change management in organizations, Applied on an educational institution" (Alexandria: Journal of the Faculty of Scientific Research, No. 2, volume 38, p. 344.

3. Al-Salem, A. (2001): organizational change and how to containment its resistance in organizations" (Cairo: Administration, the Arab Association of Administrative Sciences, . No. I, II, p. 63-64.

4. Atwater, L. E. \& Atwater, D.C. (1994) Organizational Transformation: Strategies for Change and Improvement in B. Bass and B.J. Avolio (ed.); Improving Organizational Effectiveness through Transformational Leadership. California: Thousand Oaks, Sage Publications.

5. Balogun, J. \& Hailey. H.V (1999) Exploring Strategic Change. London: Prentice Hall.

6. Buchanan, D. A. and Boddy, D. (1992) The Expertise of The Change Agent. London: Prentice Hall.

7. Certo, S. C., 1994. Modern management organizational change and stress, New York; Boston: Allyn and Bacon company, p. 300.

8. Elain Romanelli $\mathrm{P}$ Micheal Tushman, "Organizational transformation as punctuated equilibrium: an empirical test", Academy of Management Journal, Oct (1994), Vol.37, Issue.5, pp.1141-1166,p:1141.
9. Farias, G. F., \& Varma, A. (1998): "High Performance Works Systems: What we Know and What we Need to Know? "(Human Resource Planning Journal, Vol.21, pp. 50-54.

10. Gersick, C. J. G. (1991) Revolutionary Change Theories: A Multilevel Exploration of The Punctuated Equilibrium Paradigmm , Academy Of Management Review, 16(1),pp. 10-36.

11. Greenwald, J (1996) Reinventing Sears. Time, 23 (12) pp.53-75.

12. Grundy, T. (1993). Managing Strategic Change, London: Kogan

13. Hafez, E, et al (2001) Asset Management and Administration (Cairo: Ein Shams Library, p. 387.

14. Hamel, G. (2000) The leadership of the radical change - How to make the strategy already internally and automatically; Translation: Abstracts - books of the manager and businessmen (Cairo: Arab Company for Scientific Information - Shoaa, No. 187, pp 1-2

15. Handy, C (1989). The Age of Unreason, London: Arrow.

16. Incremental \& Radical Change: Definition \& Examples. (2019). Accessed from. https://study.com/academy/lesson/incrementalradical-change-definition-examples.html.

17. Kanter, R. M., Stein, BA and Jick, TD (1992) The Challenge of Organizational Change. USA: New York, Free Press.

18. Kimberley, J \& Miles, R (ed.) (1980). The Organizational Life Cycle. USA: San Francisco, Jossey Bass.

19. Lawzi, M. (1998) Trends in the Jordanian government institutions to manage change" (Amman: Journal of Studies, University of Jordan, Volume 25, No. 2, p. 339.

20. Miller, A. (1998) Strategic Management, Irwin, McGraw Hill, p. 323.

21. Mintzberg, H. (1978) Patterns in Strategy Formulation "Management Science, 24(a). pp. 93448.

22. Nadler, D., A. \& Tushman, M.L. (1990). Beyond the Charismatic Leader: Leadership \& Organizational Change. California. Regents of the University of California.

23. Nadler, D.A. \& Tushman, M.L. (1994). "Types of Organizational Change: From Incremental Improvement to Discontinuous Transformation". In D.A. Nadler, R.B. Shaw, A.E. Walton and Associates. (ed.), Discontinuous Change: Leading Organizational Transformation. San Francisco. Jossey-Bass.

24. Pettigrew, A, M., Ferlie, E. and Mckee, L. (1992) Shaping Strategic Change. London: Sage. 
25. Pettigrew, A, M., Ferlie, E. and Mckee, L. (1992) Shaping Strategic Change. London: Sage.

26. Redman. James. (2019) Managing Strategic Transformation, Managing Strategic Change, 'Change is the only constant' Heraclitus of Ephesus. Accessed from.

https://www.cpaireland.ie/CPAIreland/media/Educ ationTraining/Study\%20Support\%20Resources/201 9\%20Articles/CPA-Article-2019-Managing-

Strategic-Change.pdf

27. Romanelli, E and Tushman. M. L. (1994) Organizational Transformation As Punctuated Equilibrium: An Empirical Test, Academy of Management Journal, 37(5), pp.1141-66.

28. Senge, P. M. (1990) The Leaders New Work: Building Learning Organizations, Sloan Management Review, 32, (4) pp. 7-23.

29. Senior, B (2002). Organizational Change. England: Pearson Education Ltd.

30. Senior, B. (1997) Organisational change, Prentice Hall, London.

31. Tushman, M. \& Moore, W. (1982) Readings in The Management Of Innovation, Boston: Pitman.

32. Tushman, M.L. Newman, W.H. and Romanelli, E. (1988) Convergence and Upheaval: Managing The Unsteady Pace As The Organizational Evolution; New York: Ballinger Publishing Company.

33. Types of Groups (2013) MANAGEMENT PORTAL Accessed from.

https://managementportal.blogspot.com/2013/05/ty pes-of-groups.html?m=0.

34. Weber, B., Reichert, M., \& Rinderle-Ma, S. (2007).Change Patterns and Change Support Features in Process-Aware Information Systems. 574-588. 10.1007/978-3-540-72988-4_40.

35. Wilson, D. (1999): the strategy of change - concepts and debates in the management of change. Translation: Amara. $\mathrm{T}$ (Cairo: Dar Alfjr for publication and distribution, pp. $55-56$.

36. Wischnevsky, J. D. \& Damanpour, F. (2005). punctuated equilibrium model of organizational transformation: Sources and consequences in the banking industry. Research in Organizational Change and Development. 